\title{
Blockade of Androgen-induced Malignant Phenotypes by Flutamide Administration in Human Salivary Duct Carcinoma Cells
}

\author{
YU KAMATA ${ }^{1}$, TOMOKI SUMIDA ${ }^{1}$, RYUICHI MURASE ${ }^{2}$, HIROYUKI NAKANO ${ }^{1}$, \\ TOMOHIRO YAMADA ${ }^{1}$ and YOSHIHIDE MORI ${ }^{1}$ \\ ${ }^{1}$ Section of Oral and Maxillofacial Surgery, Division of Maxillofacial Diagnostic and Surgical Sciences, \\ Faculty of Dental Science, Kyushu University, Fukuoka, Japan; \\ ${ }^{2}$ Department of Oral and Maxillofacial Surgery, Ehime University Graduate \\ School of Medicine, Shitsukawa, Toon, Japan
}

\begin{abstract}
Background/Aim: Androgens are known to play a critical role in prostate cancer progression, but their effect on malignant phenotypes in salivary gland cancer is unclear. The androgen-androgen receptor (AR) axis may be involved in malignant phenotypes of salivary duct carcinoma (SDC) cells and therefore may be a new target for SDC treatment. To test this hypothesis, we investigated the effect of the androgen $5 \alpha$ dihydrotestosterone (DHT) on proliferation, migration, and invasiveness of SDC cells. Materials and Methods: We used a wound-healing assay to measure cell migration and a Boyden chamber invasion assay to investigate SDC cell invasive capacity. Results: DHT treatment increased cell proliferation, migration, and invasion. However, treatment with flutamide, an AR inhibitor, blocked the effects of DHT. Conclusion: These results suggest that the androgen-AR axis is involved in $S D C$ malignancy and may be an effective therapeutic target for treatment of human SDC.
\end{abstract}

The development of malignant neoplasms is a multistep process that involves many genetic and epigenetic alterations. Identifying these alterations is essential in understanding the mechanisms of cancer progression and in developing more effective methods of diagnosis and treatment. In the case of prostate cancer, hormonal stimulation is also critically involved in carcinogenesis. The androgen-androgen receptor

Correspondence to: Tomoki Sumida, Section of Oral \& Maxillofacial Surgery, Division of Maxillofacial Diagnostic and Surgical Sciences, Faculty of Dental Science, Kyushu University, 3-1-1, Maidashi, Higashi-ku, Fukuoka, 812-8582, Japan. Tel: +81 926426452, Fax: +81 926426392, e-mail: tomoki94530@gmail.com

Key Words: Androgen, cell migration, invasion, salivary duct carcinoma, steroid hormone receptors.
(AR) system plays an important role in prostate cancer progression, and AR is one of the targets for treatment of patients with prostate cancer $(1,2)$.

In the head and neck region, salivary duct carcinoma (SDC) is a rare and highly aggressive epithelial malignancy of the major and minor salivary glands, with limited evidence to guide standard treatment. Surprisingly, several immunohistochemical studies demonstrated AR expression in almost all SDCs $(3,4)$. The expression of AR is a strong prognostic factor in patients with prostate cancer and has long been used in clinical management as an indicator of endocrine responsiveness $(5,6)$.

Given the potential involvement of steroid hormone receptors in salivary gland cancer progression, we hypothesized that hormonal regulation may have an impact on SDC pathogenesis. Therefore, the strategy used for prostate cancer treatment may be effective for SDC treatment.

In this study, we determined whether or not the androgenAR axis was functional in SDC cells and assessed the effect of flutamide, an anti-androgen agent, on SDC.

\section{Materials and Methods}

Cell culture. HSY salivary gland carcinoma cells were kindly provided by Professor N. Sato of Tokushima University. This cell line was established by Professor Sato (7) from an SDC of the parotid gland. The human prostate cell lines PC-3 and LNCaP were purchased from the American Tissue Culture Collection (Manassas, VA, USA) and used as negative and positive controls, respectively. Cells were cultured in RPMI-1640 (Sigma-Aldrich, St. Louis, MO, USA) supplemented with $5 \%(\mathrm{v} / \mathrm{v})$ fetal bovine serum at $37^{\circ} \mathrm{C}$ in the presence of $5 \% \mathrm{CO}_{2}$. Fetal bovine serum was omitted in experiments in which serum-free medium was used.

Chemicals. $5 \alpha$-Dihydrotestosterone (DHT) solution $(1.0 \mathrm{mg} / \mathrm{ml}$ in methanol; Sigma Chemical Co.) was used for the experiments. For each of the following assays, cells were treated once or twice daily 
with the DHT-methanol mixture $(1 \mathrm{nM})$; control cells received $0.1 \%$ methanol only.

Flutamide (1000-fold stock; Sigma Chemical Co.) was added to ethanol to yield a final ethanol concentration of $0.1 \%$. For each of the following assays, cells were treated once or twice daily with the flutamide-ethanol mixture $(10 \mathrm{nM})$; control cells received $0.1 \%$ ethanol only for 2 days. In terms of the blockage experiment, DHT and flutamide were added to the medium at the same time; control cells received $0.1 \%$ ethanol for 2 days. Assays were performed in triplicate and the results were averaged.

Cell proliferation assay. Cell proliferative ability was determined by counting cells. Cells were digested with trypsin-ethylenediaminetetra-acetic acid at $37^{\circ} \mathrm{C}$ for $5 \mathrm{~min}$. Next, $8 \mathrm{ml}$ of conditioned medium containing $5 \%(\mathrm{v} / \mathrm{v})$ fetal bovine serum was added to the cells and the cells were collected. Then, $0.5 \mathrm{ml}$ of the supernatant was diluted with $9.5 \mathrm{ml}$ of balanced electrolyte solution. Cell number was quantified by particle counting and the analysis was performed by using a Multisizer ${ }^{\mathrm{TM}} 3$ system (Beckman Coulter, Brea, CA, USA). Assays were performed in triplicate and the results were averaged.

Cell migration assay. Cells were seeded in 6-well plates at a density of $5.0 \times 10^{5} /$ well. The following day, the bottom of each well was scratched with a pipette tip. Wells were rinsed with medium to remove detached cells, and the medium was replaced with serumfree medium. DHT (1 $\mathrm{nM})$ with or without flutamide $(10 \mathrm{nM})$ was added to the cells for $12 \mathrm{~h}$. Images of each well were acquired immediately following wound generation and again after $12 \mathrm{~h}$. Image J software (National Institutes of Health, Bethesda, MD, USA) was used to measure areas that were free of migrating cells. Experiments were performed in triplicate.

Boyden chamber invasion assay. Assays were performed in modified Boyden chambers with 8 - $\mu$ m-pore filter inserts for 24-well plates (Collaborative Research, Bedford, MA, USA). Filters were coated with 10-12 $\mu$ l of ice-cold Matrigel $^{\circledR}$ (Collaborative Research). HSY cells (40,000 cells/well) were added to the upper chamber in $200 \mu \mathrm{l}$ of serum-free medium. Cells were pre-treated with DHT with or without flutamide for 2 days (once a day). Cells were assayed in triplicate or quadruplicate, and the results were averaged. The lower chamber was filled with $300 \mu \mathrm{l}$ of conditioned medium from fibroblasts. After incubation for $20 \mathrm{~h}$, cells were fixed with $2.5 \%(\mathrm{v} / \mathrm{v})$ glutaraldehyde in phosphate-buffered saline and stained with $0.5 \%(\mathrm{v} / \mathrm{v})$ toluidine blue in $2 \%(\mathrm{w} / \mathrm{v}) \mathrm{Na}_{2} \mathrm{CO}_{3}$. Cells that remained in the Matrigel ${ }^{\circledR}$ or attached to the upper side of the filter were removed with cotton tips. Cells on the lower side of the filter were counted using light microscopy.

Western blotting analysis. Cells were lysed in $2 \times$ Laemmli buffer and stored at $-70^{\circ} \mathrm{C}$. The protein concentration was determined using the DC Protein Assay kit (Bio-Rad, Hercules, CA, USA). Samples $(20-30 \mu \mathrm{g}$ of total protein) were separated by sodium dodecyl sulfate-polyacrylamide gel electrophoresis and transferred to polyvinylidene difluoride membranes (Hybond P; Amersham Biosciences, Little Chalfont, Bucks, UK). Membranes were blocked for $1 \mathrm{~h}$ at room temperature with Tris-buffered saline with Tween20 (20 mM Tris, $137 \mathrm{mM} \mathrm{NaCl}, 3.8 \mathrm{mM} \mathrm{HCl}$, and $0.1 \%$ Tween-20) containing 5\% nonfat milk, and blots were probed with anti-AR (AR441; DAKO, Glostrup, Denmark) or anti-actin (C4; Chemicon

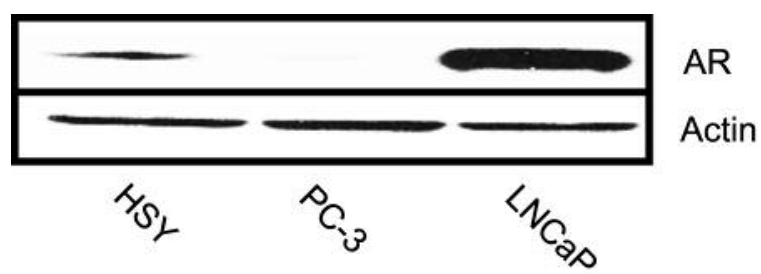

Figure 1. Androgen receptor (AR) expression in $\mathrm{HSY}, \mathrm{PC}-3$, and $L N C a P$ cell lines. Representation western blot is shown.

International, Temecula, CA, USA) antibodies for $1 \mathrm{~h}$. Membranes were washed and incubated with horseradish peroxidase-conjugated anti-mouse IgG (Santa Cruz Biotechnology, Santa Cruz, CA, USA), washed, and developed by enhanced chemiluminescence using the Amersham ECL-Plus kit (Amersham Biosciences) according to the manufacturer's instructions.

Statistical analyses. Statistical comparisons were performed using Student's $t$-test as appropriate. A $p$-value less than 0.05 was considered statistically significant. All statistical tests were performed using Statcel2 software (OMS, Tokyo, Japan).

\section{Results}

AR expression profile in cell lines. As shown in Figure 1, AR was highly expressed in LNCaP cells, whereas PC-3 cells did not express AR. HSY cells weakly expressed AR when cultured in RPMI-1640 supplemented with 5\% (v/v) charcoal-stripped serum.

Effects of DHT with and without flutamide on cell proliferation. DHT treatment induced the proliferation of HSY cells. Flutamide partially suppressed the effect of DHT on HSY cell proliferation. However, DHT-flutamide-treated cells still presented a proliferative activity similar to that of ethanoltreated control cells. The increase in proliferation induced by DHT was significantly different from that induced by ethanol or DHT plus flutamide treatment $(p<0.01$; Figure 2$)$.

Cell migration assay. Pipet scratching produced wounds of similar size in monolayers of HSY cells and control cells (Figure 3). At $12 \mathrm{~h}$ after wound infliction, a higher percentage of the scratched area was filled with cells in cultures treated with DHT than in cultures treated with DHT-flutamide or control cells ( $p<0.05$; Figure 3$)$.

Effects of DHT with and without flutamide on cell invasion. To investigate the effects of DHT on invasive properties, we plated cells in Matrigel invasion chambers. After $48 \mathrm{~h}$ of treatment with DHT with and without flutamide, the invasive capacity of DHT-treated HSY cells was markedly increased. DHT-flutamide-treated cells and ethanol-treated control cells 


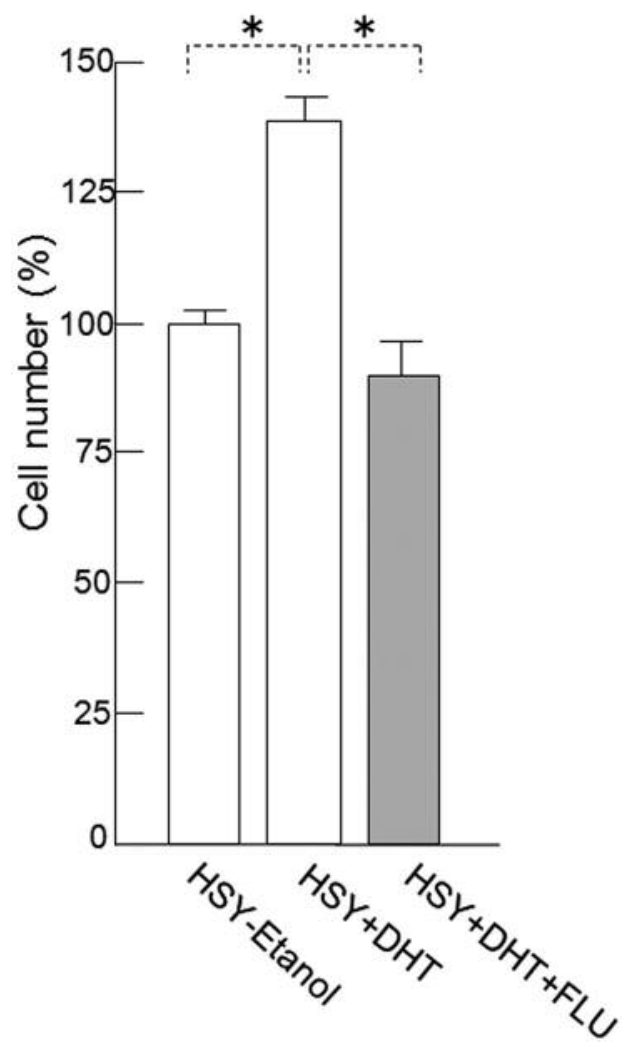

Figure 2. Effect of 5a-Dihydrotestosterone (DHT) and flutamide (FLU) on HSY cell proliferation. DHT-treated HSY cells exhibited significantly higher proliferation than cells treated with $D H T+F L U$ or with ethanol $\left({ }^{*} p<0.01\right)$. Addition of FLU inhibited the effects of DHT on HSY cell proliferation.

presented similar invasive capacities. DHT-treated cells exhibited significantly greater invasion than cells treated with DHT-flutamide or ethanol $(p<0.01$; Figure 4$)$.

\section{Discussion}

Salivary gland tumors, which account for approximately $3 \%$ of all head and neck cancer, are heterogeneous, rendering the identification of their epidemiological characteristics difficult (8). SDC is a rare, aggressive salivary gland malignancy with limited evidence available to guide standard treatment (9). Differential expression of some genes has been investigated in the different histotypes of salivary gland carcinoma (10). However, salivary gland carcinomas are divided into 24 different entities by the World Health Organization, including mucoepidermoid, adenoid cystic carcinoma, adenocarcinoma, and SDC. Malignant salivary gland tumors are difficult to treat because of their poor sensitivity to chemotherapy and radiotherapy $(11,12)$. Therefore, new treatment modalities need to be developed.
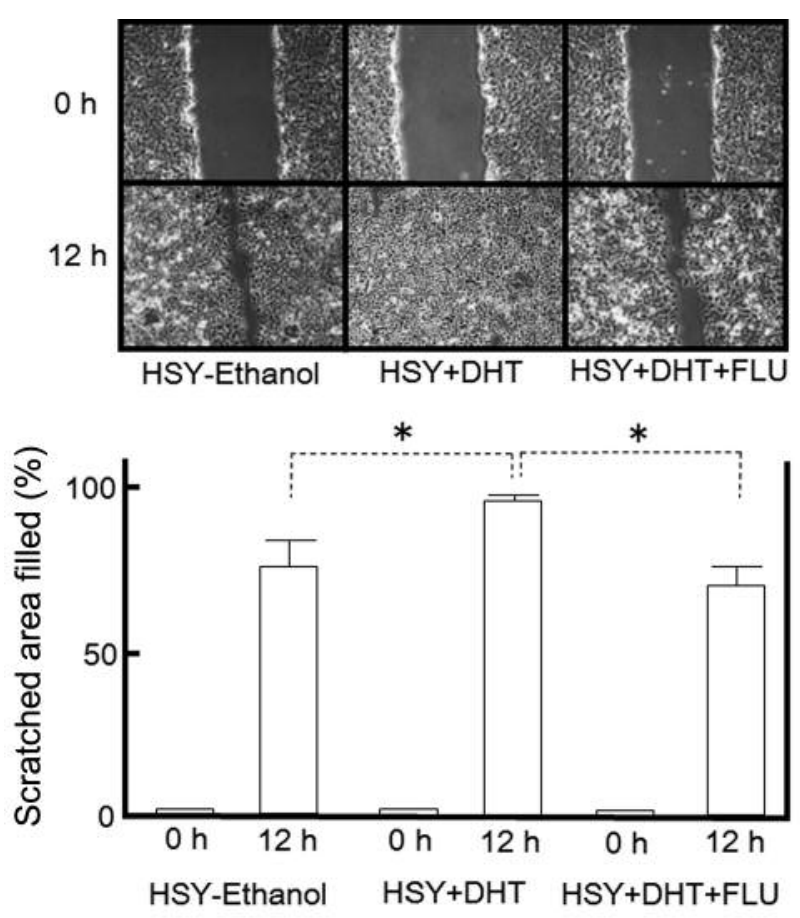

Figure 3. Effects of 5 $\alpha$-Dihydrotestosterone (DHT) and flutamide (FLU) on migration of HSY cells. At 12 h after wound infliction, a greater percentage of the scratched area was filled in cultures of DHT-treated cells than in cultures of DHT-FLU-treated and control cells $\left({ }^{*} p<0.05\right)$.

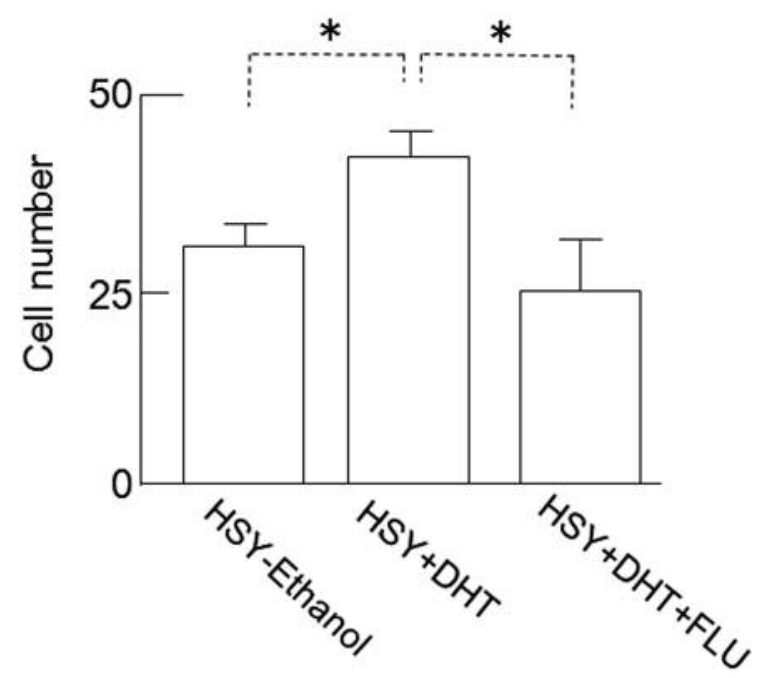

Figure 4. Effects of 5 $\alpha$-Dihydrotestosterone (DHT) and flutamide (FLU) on the invasive capacity of HSY cells. After 48 h of treatment with DHT with or without FLU, the invasive capacity of DHT-treated HSY cells was significantly higher than that of the other two groups $\left({ }^{*} p<0.01\right)$. The invasive capacity of DHT+FLU-treated cells was similar to that of ethanol-treated control cells. 
Some biomarkers associated with salivary tumors have been reported. Minichromosome maintenance 3 might be a useful proliferation marker for differential diagnosis and recognition of clinical behavior of salivary gland tumors (13). Inhibitor of differentiation 1 has been reported as a target because it reduced proliferation and invasion in aggressive human salivary gland cancer cells (14). However, application of these molecular targets for treatment is difficult. Radiotherapy immediately after surgery has been reported to improve the prognosis of patients with malignant salivary gland tumors (15).

SDC is extremely aggressive, and postoperative radiotherapy and systemic chemotherapy are not effective (11, 12). To date, surgery is considered the only treatment modality available for SDC. However, SDC is known to overexpress AR $(3,4)$, which may thus be a therapeutic target.

Given the potential involvement of steroid hormone receptors in salivary gland cancer progression, we hypothesized that hormonal regulation may impact SDC pathogenesis. Therefore, a strategy used for prostate cancer treatment may be effective for SDC treatment. Some other treatments using chemotherapy agents and proteomic analyses have been applied to prostate cancer $(16,17)$, but other treatment modalities have to be applied for SDCs.

The present study showed that the androgen-AR axis does function in SDC cells. DHT-treated HSY cells exhibited significantly higher proliferation than ethanol-treated cells. In HSY cells, AR might play a role as a transcription factor inducing proliferation. Flutamide, an AR inhibitor, suppressed the effect of DHT on proliferation. However, the inhibition was only partial and the level of proliferation after combined treatment with DHT and flutamide was similar to that of ethanol-treated cells.

In prostate cancer, an association between gene polymorphism and prostate cancer risk has been reported. For example, p27 V109G polymorphism is related to prostate carcinoma risk, and the regulatory effect of mutant $p 27$ on cell proliferation and apoptosis has been shown to be stronger than that of wild-type $p 27(p<0.05)(18)$. AR mutations have also been reported (19). However, such molecular characteristics were not investigated in the present study.

Several studies have reported that malignant salivary gland tumors present a higher rate of angiogenesis and cellular proliferation than benign tumors (20). Therefore, the inhibitory effect of flutamide on HSY cell proliferation in the present study was somewhat surprising.

In addition, we assessed other malignant phenotypes, cell migration and cell invasion. Both showed the same tendency as cell proliferation. Cell migration and invasion were induced by DHT treatment and flutamide inhibited the effect of DHT on cell invasion and migration, levels of which were similar to those of control cells.

In summary, our results using HSY cells indicate that AR is weakly expressed in SDC cells and functional, as DHT increased the proliferation, invasion, and migration of these cells, and AR inhibitor flutamide inhibited the effects of DHT. Although further experiments are needed to confirm our results, we believe that anti-AR therapy should be investigated as a hormonal therapy for SDC.

\section{Conflicts of Interest}

None.

\section{Acknowledgements}

This work was supported by the Japan Society for the Promotion of Science KAKENHI Grant Number 15K11257. We would like to thank Editage (www.editage.jp) for English language editing.

\section{References}

1 Zarif JC and Miranti CK: The importance of non-nuclear AR signaling in prostate cancer progression and therapeutic resistance. Cell Signal 28: 348-356, 2016.

2 Foley $\mathrm{C}$ and Mitsiades N: Moving beyond the androgen receptor (AR): targeting AR-Interacting proteins to treat prostate cancer. Horm Cancer 7: 84-103, 2016.

3 Fan CY, Wang J, and Barnes EL: Expression of androgen receptor and prostatic specific markers in salivary duct carcinoma: an immunohistochemical analysis of 13 cases and review of the literature. Am J Surg Pathol 24: 579-586, 2000.

4 Williams MD, Roberts D, Blumenschein GR Jr., Temam S, Kies MS, Rosenthal DI, Weber RS and El-Naggar AK: Differential expression of hormonal and growth factor receptors in salivary duct carcinomas: biologic significance and potential role in therapeutic stratification of patients. Am J Surg Pathol 31: 16451652, 2007.

5 Roach M 3rd, Ceron Lizarraga TL and Lazar AA: Radical Prostatectomy Versus Radiation and Androgen Deprivation Therapy for Clinically Localized Prostate Cancer: How Good Is the Evidence? Int J Radiat Oncol Biol Phys 93: 1064-1070, 2015.

6 Tamburrino L, Salvianti F, and Marchiani S, Pinzani P, Nesi G, Serni S, Forti $G$ and Baldi E: Androgen receptor (AR) expression in prostate cancer and progression of the tumor: Lessons from cell lines, animal models and human specimens. Steroids 77: 996-1001, 2012.

7 Myoken Y, Myoken Y, Okamoto T, Kan M, McKeehan WL, Sato JD and Takada K.: Expression of fibroblast growth factor-1 (FGF-1), FGF-2 and FGF receptor-1 in a human salivary-gland adenocarcinoma cell line: evidence of growth. Int J Cancer 65: 650-657, 1996

8 Altinay S, Taskin U, Sar M, Aydin S and Oktay MF: Histopathological diversity in parotidectomy materials in Turkish population: clinicopathologic analysis and demographic features of 136 cases in a tertiary care hospital. Asian Pac J Cancer Prev 15: 5701-5707, 2014.

9 Gilbert MR, Sharma A, and Schmitt NC, Johnson JT, Ferris RL, Duvvuri U and Kim S: A 20-Year Review of 75 Cases of Salivary Duct Carcinoma. JAMA Otolaryngol Head Neck Surg 03, 2016. doi:10.1001. 
10 Gobel G, Szanyi I, Revesz P, Bauer M, Gerlinger I, Nemeth A, Ember I, Gocze K, and Gombos K: Expression of NFkB1, GADD45A and JNK1 in Salivary Gland Carcinomas of Different Histotypes. Cancer Genom Proteom 10: 81-87, 2013.

11 Andry G, Hamoir M, Locati LD, Licitra L, and Langendijk JA: Management of salivary gland tumors. Expert Rev Anticancer Ther 12: 1161-1168, 2012.

12 Nakashima T, Yasumatsu R, Toh S, Hashimoto K, Shinoto M, Nakamura $\mathrm{K}$ and Komune $\mathrm{S}$ : Is there a role of adjuvant treatment for salivary duct carcinoma? J Laryngol Otol 129: S98-101, 2015.

13 Ashkavandi ZJ, Najvani AD, and Tadbir AA, Pardis S, Ranjbar MA and Ashraf MJ: MCM3 as a novel diagnostic marker in benign and malignant salivary gland tumors. Asian Pacific J Cancer Prev 14: 3479-3482, 2013.

14 Sumida T, Murase R, and Onishi-Ishikawa A, McAllister SD, Hamakawa $\mathrm{H}$ and Desprez PY: Targeting ID1 reduces proliferation and invasion in aggressive human salivary gland cancer cells. BMC Cancer 13: 141, 2013.

15 Kaur J, Goyal1 S, and Muzumder S, Bhasker S, Mohanti BK and Rath GK: Outcome of surgery and post-operative radiotherapy for major salivary gland carcinoma: Ten-year experience from a single institute. Asian Pac J Cancer Prev 15: 8259-8263, 2014.
16 Chen X, Liu Y, Wu J, Huang H, Du Z, Zhang K, Zhou D, Hung $\mathrm{K}$, Goodin S and Zheng XI: Mechanistic study of inhibitory effects of atorvastatin and docetaxel in combination on prostate cancer. Cancer Genom Proteom 13: 151-160, 2016.

17 Green JE, Cooperwood JS, Taka E, Soliman KF, Goodman CB and Reams RR: Comparative proteomic analysis reveals growth inhibition by 3-N-alkyloxyestradiol derivative (SERM) in prostate cancer cells. Cancer Genom Proteom 11: 195-200, 2014.

18 Han QH, Shan ZJ, Hu JT, Zhang N and Zhang XP: Relationship between gene polymorphisms and prostate cancer risk. Asian Pac J Trop Med 8: 569-573, 2015.

19 Suh JH, Chattopadhyay A, Sieglaff DH, Storer Samaniego C, Cox MB and Webb P: Similarities and distinctions in actions of surface-directed and classic androgen receptor antagonists. PLoS One 10: e0137103, 2015.

20 Tadbir AA, Pardis S, Ashkavandi ZJ, Najvani AD, Ashraf MJ, Taheri A, Zadeh MA and Sardari Y: Expression of Ki67 and CD105 as proliferation and angiogenesis markers in salivary gland tumors. Asian Pac J Cancer Prev 13: 5155-5159, 2012.

Received April 9, 2016

Revised May 18, 2016

Accepted May 24, 2016 